WellBeing International

WBI Studies Repository

1986

\title{
Effects of Early Experience Upon Adaptiveness of Horses
}

J. C. Heird

Texas Tech University

R. W. Bell

Texas Tech University

S. G. Brazier

Texas Tech University

Follow this and additional works at: https://www.wellbeingintlstudiesrepository.org/acwp_ewp

Part of the Animal Studies Commons, Behavior and Ethology Commons, and the Comparative

Psychology Commons

\section{Recommended Citation}

Heird, J.C., Bell, R.W., \& Brazier, S.G. (1986). Effects of early experience upon adaptiveness of horses. In M.W. Fox \& L.D. Mickley (Eds.), Advances in animal welfare science 1986/87 (pp. 103-109). Washington, DC: The Humane Society of the United States.

This material is brought to you for free and open access by WellBeing International. It has been accepted for inclusion by an authorized administrator of the WBI Studies Repository. For more information, please contact wbisr-info@wellbeingintl.org.

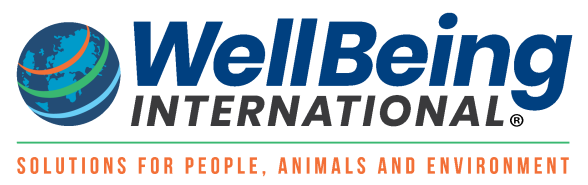




\title{
EFFECTS OF EARLY EXPERIENCE UPON ADAPTIVENESS OF HORSES ${ }^{1,2}$
}

\author{
J.C. Heird ${ }^{3}$, R.W. Bell ${ }^{4}$, \\ and S.G. Brazier ${ }^{5}$
}

\section{Introduction}

The early rearing management of horses varies greatly. Whereas most breeding farms handle horses on a practically continuous basis, many horses reared on the working ranches of the southwestern United States may have experienced minimal contact with humans prior to being trained. Indeed, rearing horses with conspecifics in holding ranges which may be several hundred, or even several thousand, acres in extent mimics the habitat of the feral horse. Extensive contact with humans frequently occurs only following two to three years of free grazing, thus the subsequent process of training as work animals entails considerable stress both on horses and their human owners. An additional concern with this type of rearing is the high level of attrition of stock due to accidental injury, predation, etc. Death losses of greater than $10 \%$ are not uncommon.

Experimentation with laboratory animals, encompassing the range of usual species (mice, rats, cats, dogs, and primates), has conclusively demonstrated that handling by humans during early life facilitates subsequent development in terms of health and viability, reduced emotional reactivity, more adaptive responses to a variety of stressors (both biological and behavioral adaptations), and increased ability to adapt to changing circumstances as exemplified by increased ability to learn and solve problems (see M. Bornstein 1985, for recent review).

Two studies (described below) (Heird et al. 1981; Whitaker 1982) conducted at Texas Tech University (TTU) have extended these findings regarding the beneficial effects of early handling from laboratory animal species to domestic horses. The findings (reported below) suggest that a moderate amount of handling of young horses increases their learning ability as measured by maze-learning tasks and estimates of trainability under saddle, decreases the stress (both for horses and human trainers) associated with confining and training the horse under saddle, and possibly, reduces attrition during the initial years of rearing. This latter result is suggested by our data. More extensive sampling is necessary before it can be stated as a conclusion. 


\section{Methods}

In the first experiment, three groups of 10 horses each were obtained from three sources which differed in the amount of early handling provided to the young horses. Horses in the first group, obtained from a large Texas ranch, were virtually unhandled. Their only human contact was three days of haltering as foals and minimum contact necessary to wean them at approximately eight months of age. Otherwise they were reared under range conditions. Horses in the second group, obtained from a ranch in eastern New Mexico, were handled as sucklings and frequently associated with humans. At weaning, horses were individually stalled, haltered, and gentled for one week. Following weaning, horses were housed in small corrals from which they were led, restalled, and groomed weekly. Horses in the third group were reared in small corrals on the TTU campus. At three months of age these horses were haltered, weaned, and handled by students an average of four times weekly for a ten-month period (August through May).

In the second experiment, 40 Quarter Horses were obtained from the same ranch that provided the virtually unhandled horses of the initial study. They were selected at weaning and individuals were assigned randomly to one of five conditions. These five conditions were (1) no handling except movement from one range to another, (2) one week of handling at weaning, (3) two weeks of handling at six-month intervals, (4) three weeks of handling at six-month intervals, and (5) nearly continuous handling for 18 months while housed at the TTU Horse Center. Handling for all horses consisted of haltering, leading, grooming, tying to an overhead cable, and routine care. Groups 2, 3, and 4 were reared under range conditions between handling sessions as were horses from Group 5 following the 18 months of handling. All horses were pastured together before returning to the TTU Horse Center for testing. Horses from Group 1 were halter broken prior to transport to the Horse Center.

Behavioral testing consisted of trainability ratings obtained following 10 days of habituation to a T-maze, performance in an alternation place learning task in the T-maze, and trainability ratings of performance when tested under saddle training subsequent to completion of the maze test.

The T-maze (figure 1) was constructed indoors of plywood walls measuring 2.44 meters in height. Each goal branch contained a feed tub and an exit door. During habituation, horses individually explored the maze for 10 minutes for 10 consecutive days, following which a panel of raters, who had observed the habituation trials and had handled the horses, assigned each a rating from 1 (quick learner) to 4 (slow learner). Following habituation, the horses were tested individually each day for 20 days in an alternation place learning task. Feed was placed in alternate goal arms of the maze on successive days, requiring that the horses learn a daily alternation of place. During each trial a horse was led to the maze entrance and released. When the horse had passed the choice point the response was recorded, the handler entered the maze, caught the horse and led it through the exit door and around the outside of the maze to the entrance. The route back to the 


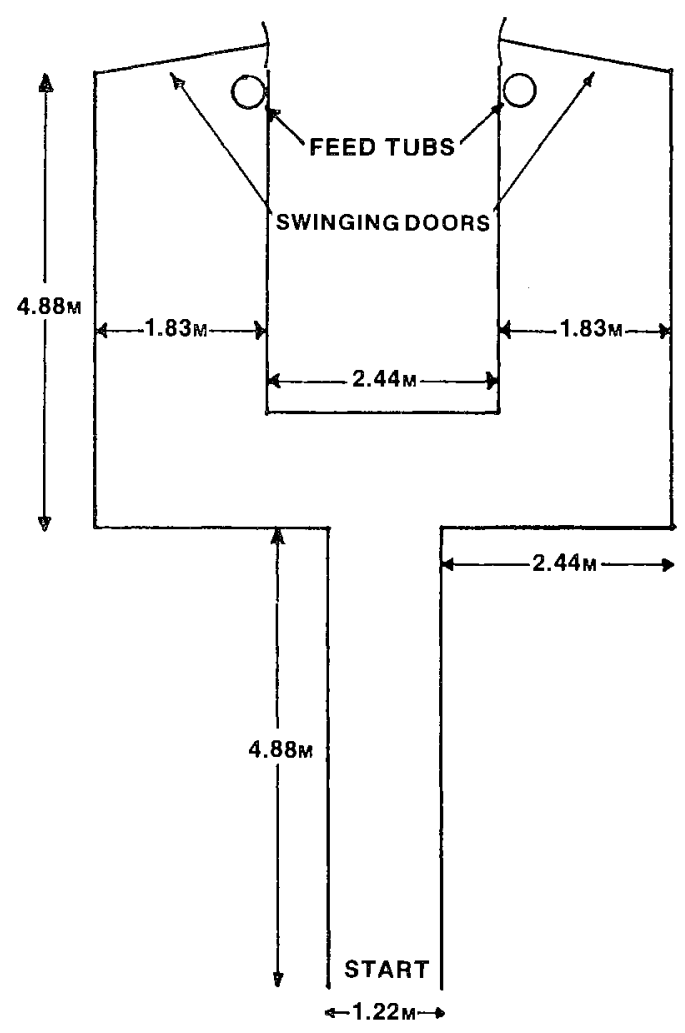

Figure 1. Diagram of maze apparatus.

entry was a random clockwise/counterclockwise sequence. Each horse received trials until it attained a criterion of 11 correct responses in a series of 12 consecutive trials with eight consecutive correct trials. A horse was retired for the day following attainment of criterion or 30 trials maximum.

\section{Results}

Figures 2 and 3 present mean maze performance for the first experiment. Group 2 animals (intermediate amount of handling) scored the highest percentage of correct responses, $92 \%$ on day 19, followed by Group 3 (most handled) with $78 \%$ on day 19 . Group 1 (unhandled) persevered in entering the same goal arm on all days, thus their pattern of percentage correct reflects high and low scores on alternate days with no improvement across the 20 days. The mean trials to criterion per day reflect the same pattern as percentage correct per day. The results suggest that the unlandled animals failed to learn the place response. Both groups of handled horses exhibited learning with the intermediate amount of handling being somewhat superior 
to intensive/extensive handling. All differences were statistically significant at the $P<.05$ level. There were some indications that Group 3 (most handled) may have simply become bored as the test did not provide the necessary stimulus novelty for the entire 20 day period.

Results of the second experiment approximate those of the initial study. Mean performance of all groups of horses showed no change across the last 10 days of testing, indicating that any learning already had occurred during the

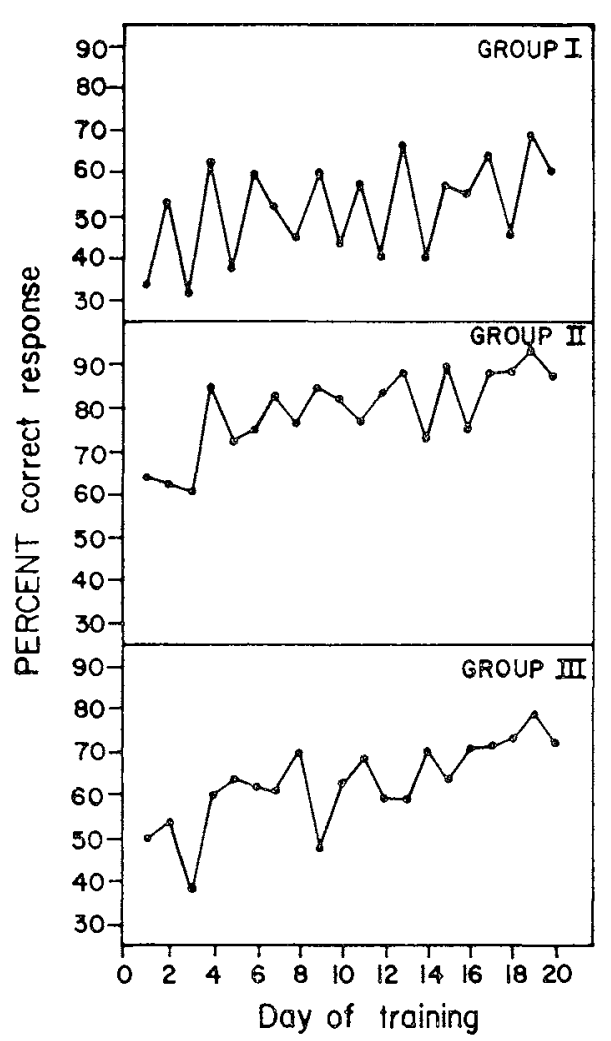

Figure 2. Percent correct responses by group and day of training, experiment 1 .

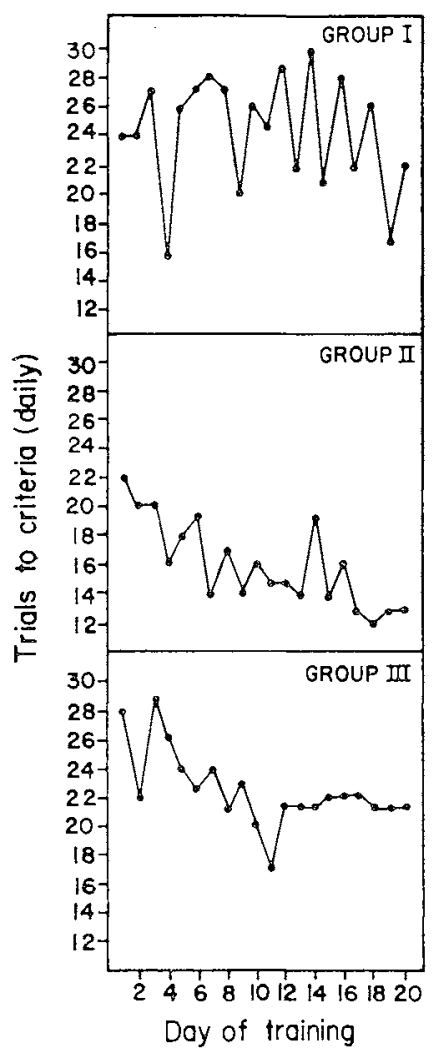

Figure 3. Trials to criterion by group and day of training, experiment 1.

initial 10 days of testing. Performance during the first 10 days reflected the effects of amount of handling. Group 5 (most handled) averaged $65 \%$ correct choices while Group 1 (unhandled) averaged 56\% correct choices, with the remaining (intermediately handled) groups being intermediate $(P<.05)$. Group 5 horses also required fewer trials to criterion during daily testing than did other groups $(P<.05)$. 
Trainability scores, assigned following the habituation-to-maze trials, also reflected the effects of handling. In the first experiment, animals of Group 2 (intermediate handling) received highest average ratings, followed by Group 3 with Group 1 (unhandled) receiving lowest ratings. These ratings, when assigned to animals of the second experiment, paralleled the ratings of the first study. Handled horses received higher average ratings than did unhandled, with animals of Group 4 (three weeks of handling) receiving the highest average rating.

Horses of the second experiment were trained under saddle, with four experienced horsemen rating their trainability. Animals of Group 5 received superior trainability scores when compared to other groups $(P<.05$; see figure 4).

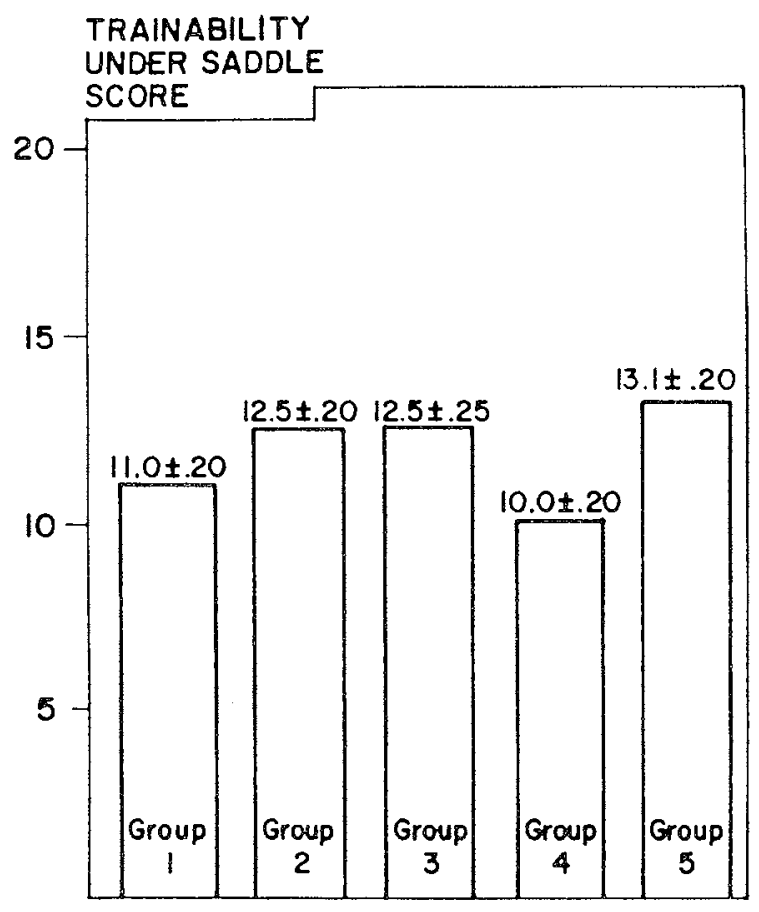

Figure 4. Trainability under saddle scores by group, experiment 2 .

\section{Discussion}

The results of the experiments reported here are consistent with data on laboratory animal species which show augmented learning ability as a function of early handling. Although the systematic tests of effects focused upon learning, additional less systematic data suggest some additional and/or related effects. The ratings of trainability obtained during maze-habituation 
incorporate such animal behaviors as flinching, lunging, head tossing, etc., suggesting that the ratings reflect appraisals of emotionality as well as training aptitude. These same behaviors, of course, interact with the estimates of trainability under saddle. Furthermore, the student handlers reported that the unhandled horses appeared to be fearful of entering the maze and required strenuous effort on the part of the handlers to be engaged in the task. It may well be that differences in learning reflect, to a great extent, differences in emotional reactivity to a novel situation, which is consistent with the data on laboratory species.

Additional estimates of handling-induced differences were obtained from cowboys engaged in "breaking" the experimental animals to saddle. These horsemen were not trained animal scientists and indeed were skeptical of the professors and their so-called science to the point of vocal ridicule. After breaking the horses to saddle, the horsemen were asked to rate the horses' quality as potential work animals on a scale of their own devising (1 to 20 points), with no prior knowledge of the handling background of the animals. Their ratings consistently were higher for early-handled as opposed to unhandled horses with the ratings correlating substantially with scores obtained in the maze test. Many spontaneously commented that these horses (Group 5 and to a lesser extent, other handled groups) were "the best horses we've ever worked."

An effect of handling on attrition rate is another point of interest, although it is suggestive, at most, with these small samples. Unhandled groups averaged three losses each during the early years on the range. The handled groups sustained losses ranging from zero to one, with no losses in Group 5. If we can generalize from studies of laboratory rodents, the effects of handling should reduce the reactivity of horses to unexpected events, possibly reducing running panic and accidental injury or death.

\section{Conclusions}

Based on these two studies it appears that early handling by humans can significantly alter a horse's temperament/trainability in the direction of less emotional and more trainable. The data suggest that this is reflected not only in laboratory measures of these behaviors, but also in the horse's reactivity to being trained as saddle animals and, possibly, in increased survival ability under range conditions. Although these results must be interpreted tentatively until additional data under less artificial conditions are obtained, the cowboys, foreman, and ranch manager of the cooperating ranch moved from a position of open disbelief and derision to one of endorsement. This change is reflected not only in their verbal interactions, but also in the decision (implemented) to hire a "handler" and revise their rearing management procedures in keeping with the recommendations stemming from the studies. 


\section{Endnotes}

${ }^{1}$ Approved by the Dean of the College of Agricultural Science, Pub. No. T-5-184.

${ }^{2}$ Supported in part by funds appropriated by the Houston Livestock Show and Rodeo and the Institute of Agriculture, Texas Tech University.

${ }^{3}$ Assistant Professor, Dept. of Animal Science, Texas Tech University, Lubbock, TX 79409. Current address: Dept. of Animal Science, Colorado State University, Fort Collins, CO 80523.

${ }^{4}$ Professor, Dept. of Psychology, Texas Tech University.

${ }^{5}$ Graduate Student, Dept. of Animal Science, Texas Tech University.

\section{References}

Bornstein, M. 1985. Sensitive Periods in Development: Interdisciplinary Perspectives. Hillsclale, Ny: Lawrence Erlbaum Associates, Inc.

Heird, JC, Lennon, AM and Bell, RW. 1981. Effects of early experience on the learning ability of yearling horses. J. Anim. Sci. 53:5.

Whitaker, DD. 1982. Effects of varying amounts of early handling at weaning and later ages on the subsequent learning ability of two-year-old horses. Ph.D. Thesis. Texas Tech University. 